\title{
DIE BETEKENIS WAT KOMMUNIKASIEKUNDE VIR DIE PREDIKING KAN HE
}

\author{
Prof. H. P. Fourie (Unisa)
}

\section{Kommunikasiekunde}

Kommunikasiekunde is een van die jongste wetenskappe wat in die area van geesteswetenskappe ontstaan het. Dit is 'n vak wat eintlik ontstaan het uit die samevoeging van verskeie vertakkings wat vandag almal as onderafdelings van die Kommunikasiekunde beskou word. Die heel oudste hiervan is die retoriek soos dit al van voor Christus af deur die Grieke geleer is. In die meer resente verlede was Joernalistiek meer as dikwels die voorloper van huidige kommunikasiekunde-departement gewees.

In Suid-Afrika onderskei ons die volgende studievelde: Pers, Radio, Rolprent, Televisie, Skakelwese, Reklame, Diplomasie, Inligtingswese, Organisasiekommunikasie, Interkulturele kommunikasie en Groepmedia.

Die vernaamste navorsingsmetode in die Kommunikasiekunde is inhoudsontleding en selfs dié word sterk ontwikkel in twee hoofrigtings - die „V.S.A.-benadering” wat meer statisties georiënteer is en die "Europese benadering" wat meer semiologies struktureel van aard is.

\section{Kommunikasie}

Wat is kommunikasie? Hoekom is dit so moeilik om die handeling van mense te beskryf of te definieer? Dit is miskien die handeling waarin ons as mense die meeste betrokke is en tog vind ons in feitlik elke boek oor kommunikasie 'n nuwe of 'n gewysigde definisie daarvan. Guido Fauconnier het vir sy boek Massamedia en Samenleving vyftig verskillende definisies ontleed en toe sy eie opgestel.

Prof. Marthinus van Schoor het ook die veld verken en met 'n kort beskrywing - definisie as $\mathrm{u}$ wil - voor die dag gekom. Hy sê kommunikasie is die verkeer van mededeling en vertolking van boodskappe. Hieruit volg 'n paar afleidings wat noodsaaklik is vir ons bespreking van Kommunikasiekunde en prediking:

Eerstens moet dit duidelik wees dat kommunikasie 'n handeling is. Tweedens is daar twee partye in die handeling betrokke - die mededeler en 'n vertolker.

Derdens vind twee soorte handelinge plaas - dié van mededeling en dié van vertolking.

Vierdens is daar 'n ,verkeer" in die kommunikasiesituasie wat van daardie situasie 'n dinamiese proses maak. 'n Proses wat plaasvind tussen mededeler en vertolker.

Vyfdens en laastens, is die proses of die verkeer tussen daardie twee partye gemoeid met boodskappe. Daar is 'n uitruil van boodskappe in 'n kommunikasieproses aan die gang. 


\section{Kommunikasiemodelle}

Om die relatief moeilike proses beter te verstaan is daar oorgegaan na die ontwerp van modelle wat die kommunikasieproses moet verduidelik en wat die interaksie tussen die verskillende komponente moet uitbeeld.

In 1949 stel Shannon en Weaver die sogenaamde Wiskundige model op:

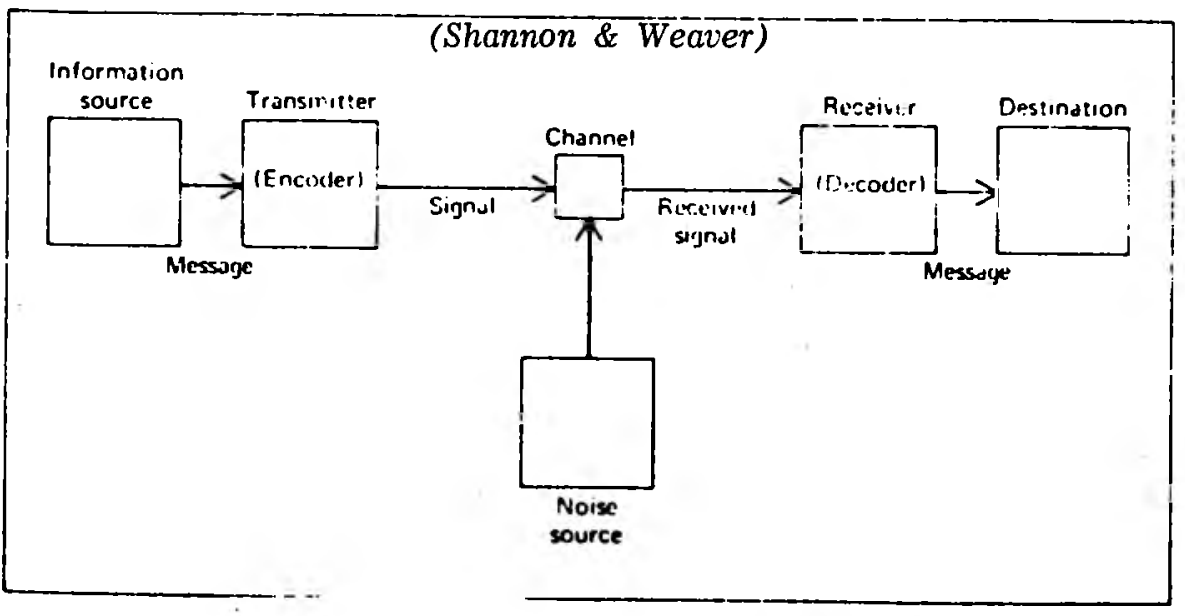

A mathematical model of communication.

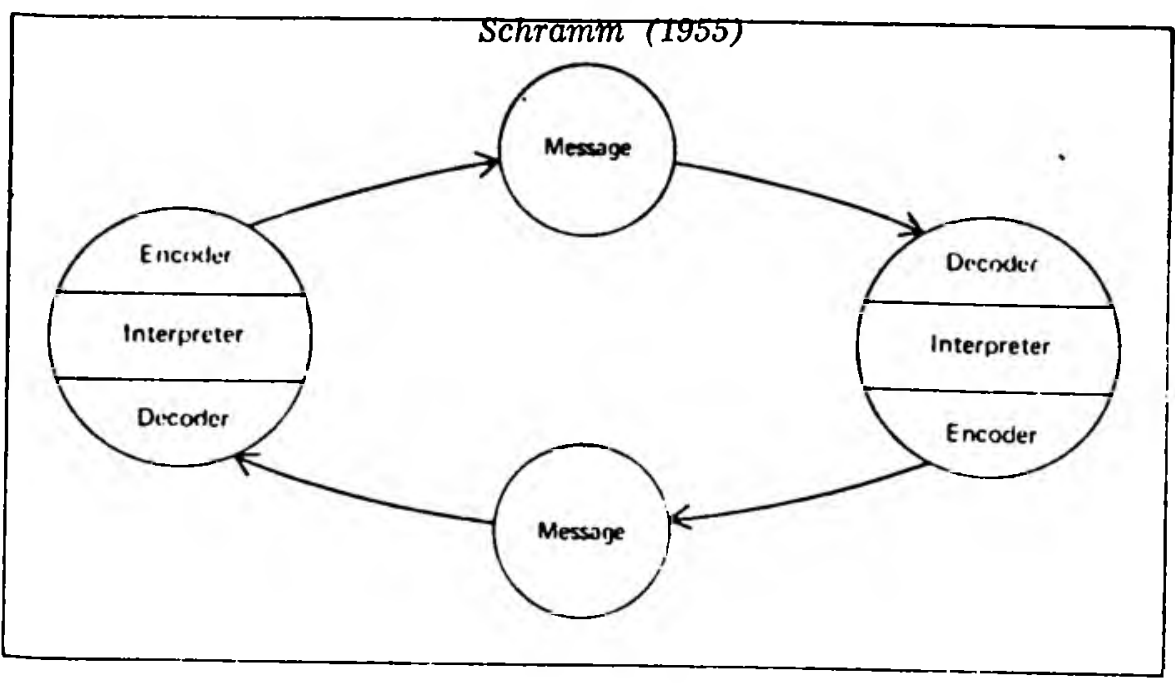

Schram's model of communication. 
Becker (1968)

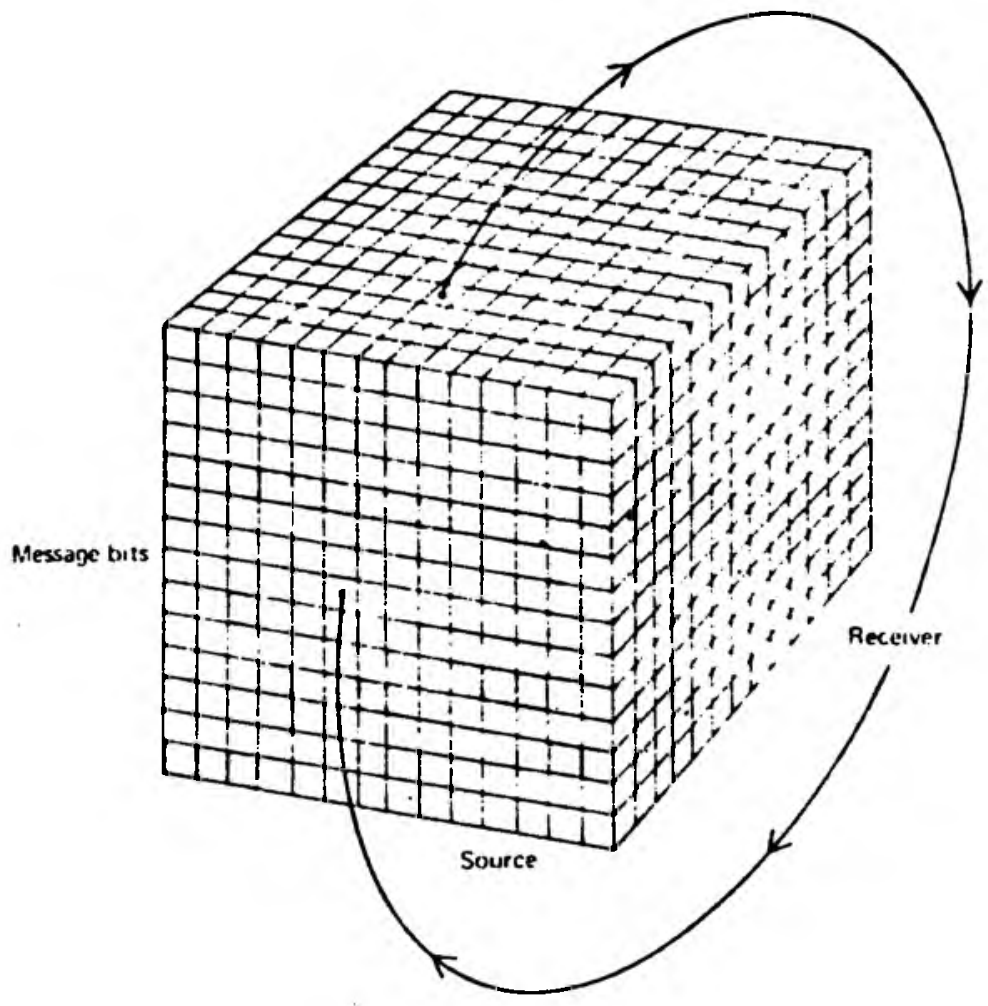

A mosaic model of communication 
Ruesch and Bateson (1951)

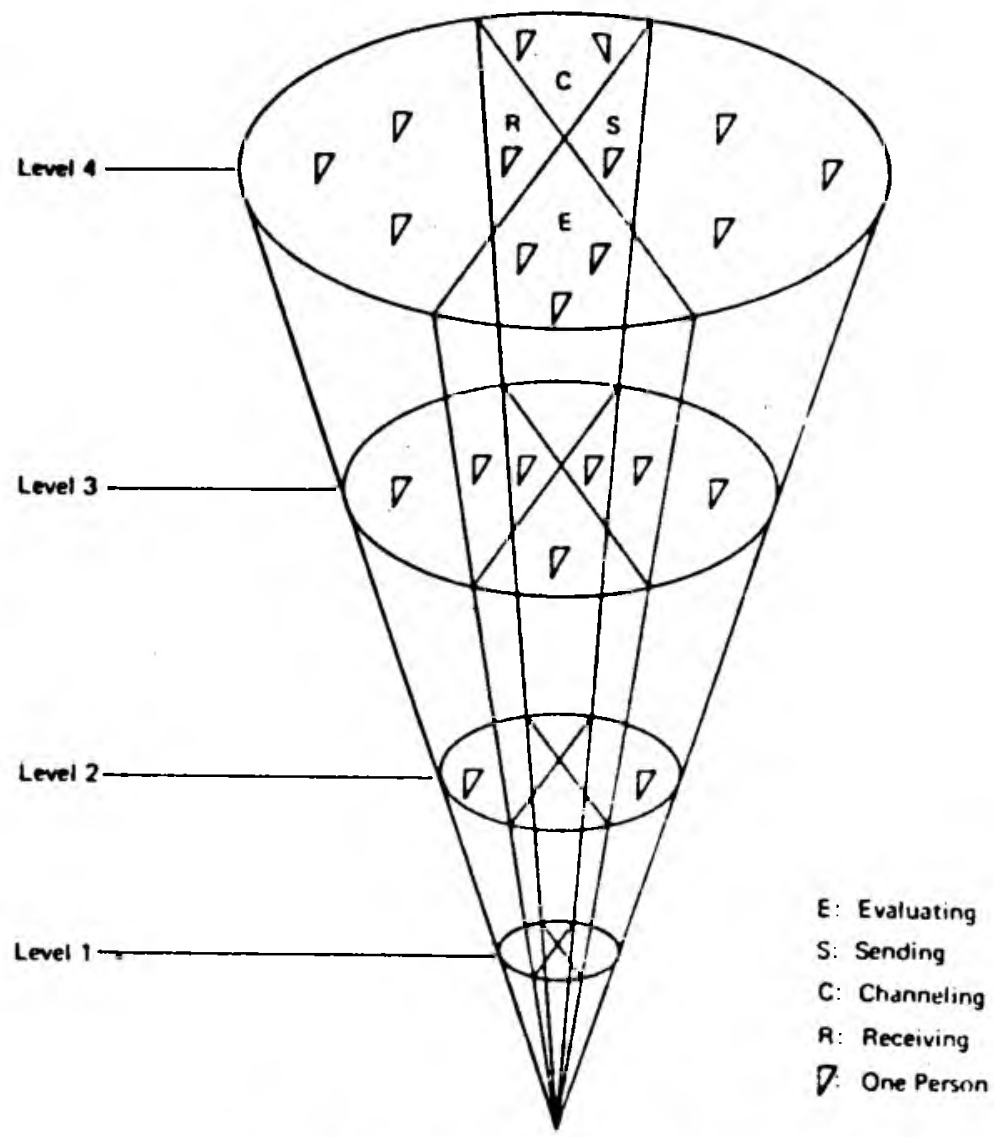

The functional model of communication 


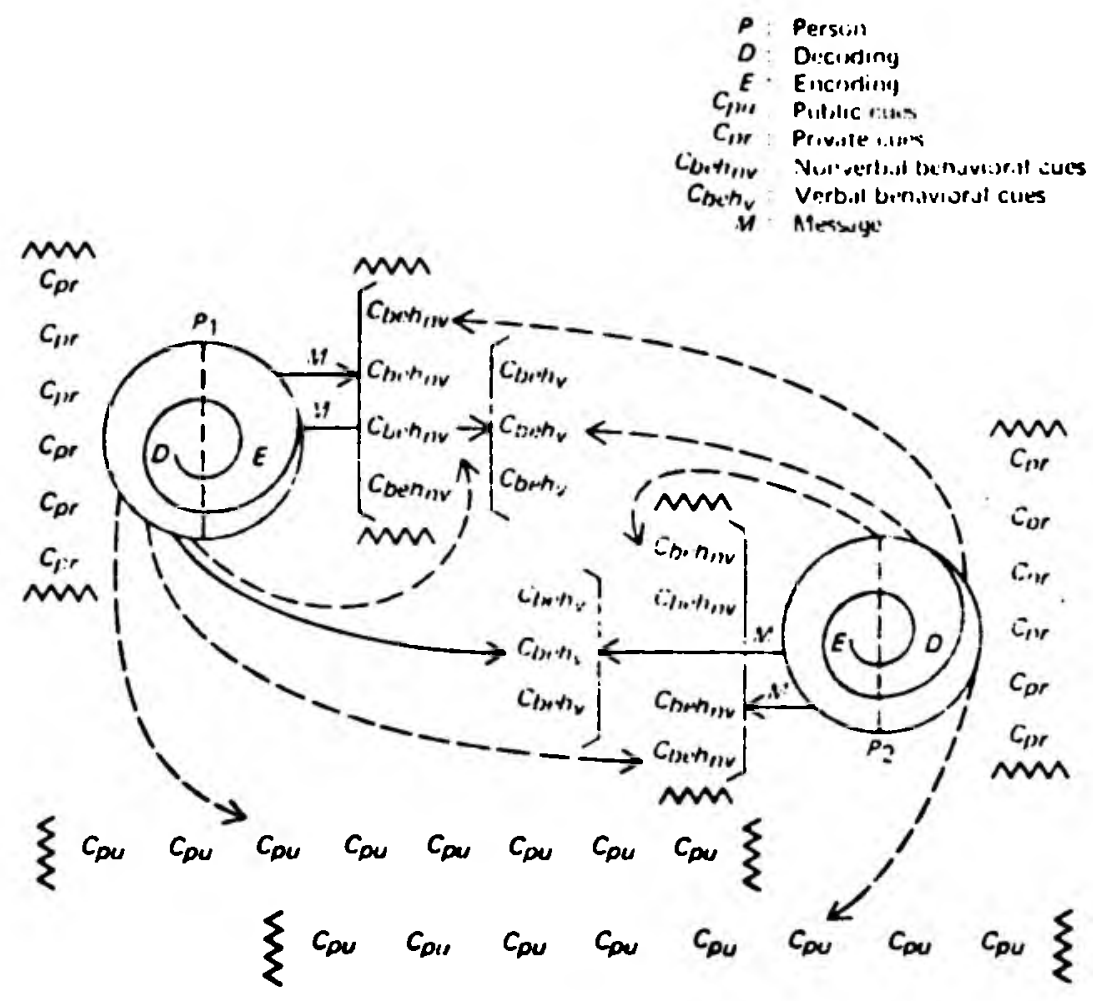

A transactional model of interpersonal communication. 


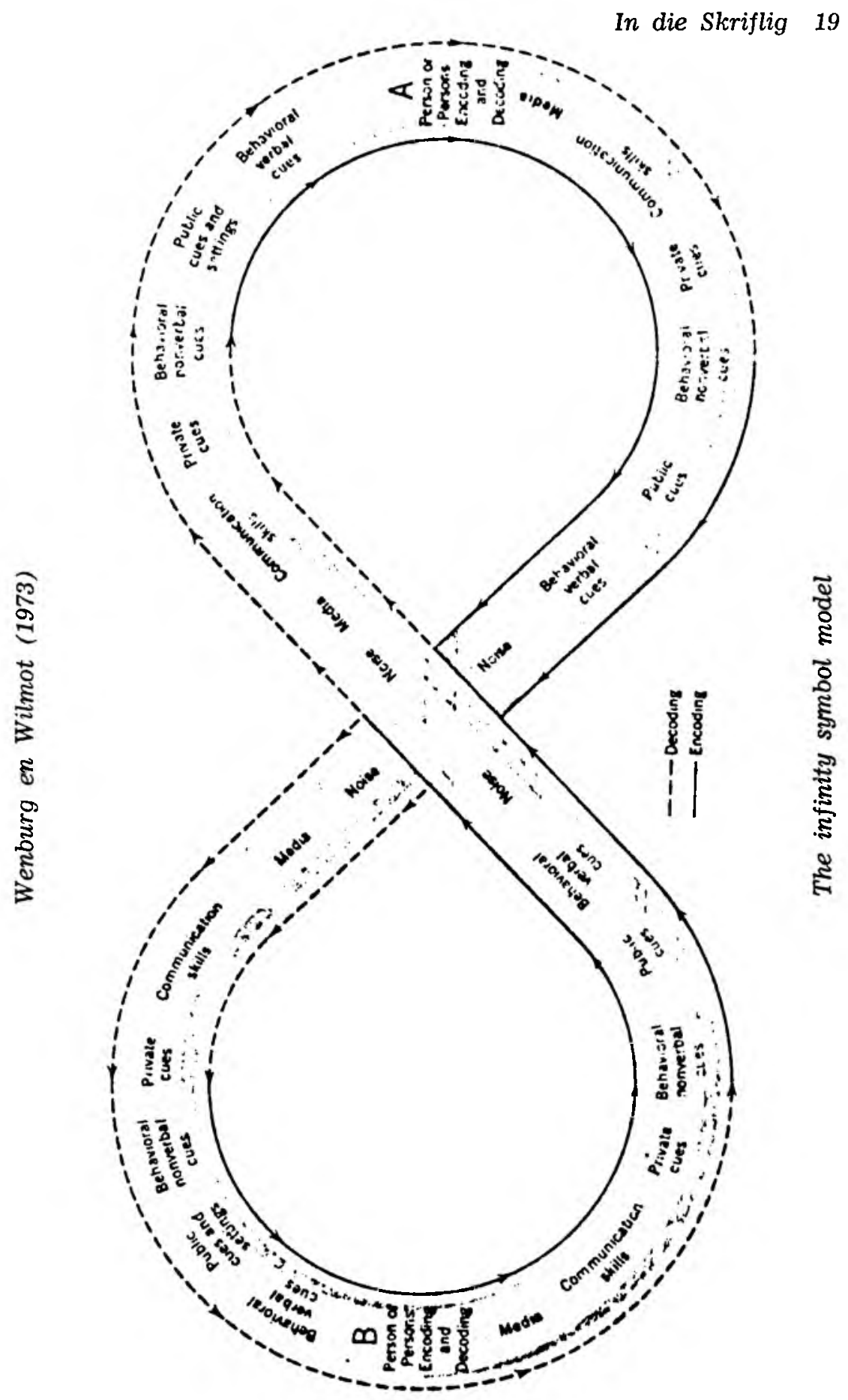


Dit is nie my doel om al hierdie modelle te bespreek nie maar ek moet met $u$ die verskillende komponente van 'n kommunikasiesituasie bespreek sodat ons duidelikheid het oor terminologie wat verder aan gebruik sal word. Vir dié doel verwys ek u na Schoor se Analitiese Model van Kommunikasie.

Van Schoor (1977)

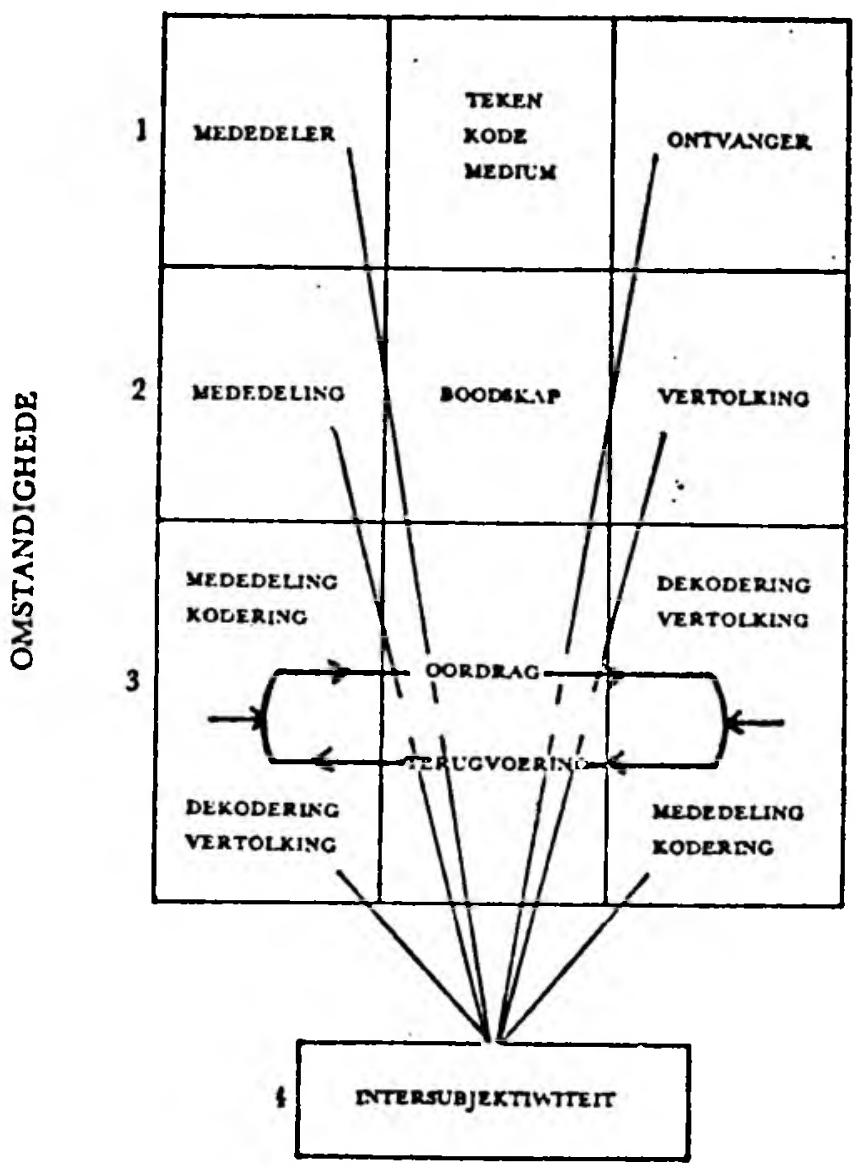


In Van Schoor se model kry ons drie basiese vlakke wat elk uit drie komponente bestaan:

Mededeler: In die prediking-kommunikasiesituasie is die predikant op die oog af die Mededeler. Ek is bewus daarvan dat daar ander opvattings hieroor is, maar ek kom later hierop terug.

Teken, kode, medium: Hierdie is 'n komplekse komponent - multidimensioneel. Ons kan nie kommunikeer sonder 'n medium.

In prediking is die medium in fisiese terme klankgolwe maar vir die argument reduseer ons dit na spraak. Geen gesprek kan sonder tekens of kodes plaasvind nie en in die prediking is dit woorde - d.w.s. taal en sekere ander nie-verbale of semiologiese kodes.

Ontvanger: Dit is almal wat ' $n$ boodskap ontvang maar ons moet ' $n$ onderskeid tref tussen ontvangers en bestemming. Die bestemming van ' $n$ boodskap is daardie mense vir wie dit bedoel is. Diegene wat in staat is om die boodskap te ontvang en te vertolk en wie 'n behoefte aan die boodskap het.

Mededeling: In terme van die prediking kan ons die mededeling sien as die hele preek.

Boodskap: Die kern betekenis van die preek. Dit is natuurlik moontlik om meer as een boodskap in 'n mededeling te hê. Dit is met boodskappe en die mededeling of oordra van boodskappe dat die Kommunikasiekunde hom primêr besig hou.

Vertolking: Die betekenistoeskrywing van die ontvanger. 'n Kommunikator streef daarna om sy boodskap so te kodeer dat die ontvanger dieselfde vertolking daaraan sal gee as wat hyself daaraan gee.

Kodering: Dit is die proses waartydens die mededeler of kommunikator sy boodskap in waarneembare tekens en simbole omsit. Die woorde, gebare, stemtoon, spreektempo wat die predikant in sy preek gebruik.

Dekodering: Die proses waartydens die ontvanger die mededeling omskakel en betekenisse daaraan gee wat binne sy bevattingsvermoë val.

Oordrag en Terugvoering: Die proses waartydens die mededeler sy mededeling mak ooreenkomstig die eise van die kode en die medium wat gebruik word asook die eise van die omstandighede waarin die kommunikasie plaasvind. „Oordrag" word gebruik om die rigting: mededeler na ontvanger aan te dui terwyl "Terugvoering" gebruik word om die rigting: ontvanger na mededeler aan te dui. Laasgenoemde is die respons van die ontvanger op die mededeler se boodskap nadat hy dit vertolk het. Die terugvoering is terugvoering slegs vir die mededeler. Vir die ontvanger is dit natuurlik 'n mededeling of boodskap en vir homself of van sy kant gesien is hy natuurlik ' $n$ mededeler of kommunikator in sy eie reg.

Intersubjektiwiteit is ' $n$ sintese van al bogenoemde komponente én die omstandighede waarin die kommunikasie plaasvind. 
Omstandighede: Persoonlik onderskei ek (en ek wil dit nie lê voor die deur van kollega Van Schoor nie) tussen makro- en mikro-omstandighede:

Makro-omstandighede is die totale sosiale omstandighede waarin 'n mededeling gemaak word: Die wêreldtoestand, die omstandighede in die land, die toestand waarin ' $n$ volk homself bevind, die ekonomiese klimaat, ens.

Mikro-omstandighede is die werklike fisiese omstandighede waarin 'n mededeling gemaak word: die kerkgebou, die soort sitplekke, of dit reën of sonskyn is, of dit warm of koud is, of 'n kind huil of nie, ens., ens.

Alle omstandigheidsfaktore kan 'n invloed op die doeltreffendheid van 'n mededeling hê.

Verdeling: Ons onderskei binne die kommunikasiekunde twee hoofrigtings, t.w. die Teoretiese en die Praktiese. Die twee kan natuurlik nie los van mekaar staan nie maar dit is tog ' $n$ handige funksionele verdeling.

Teorieë, of as $u$ wil, wysgerige besinning in die kommunikasiekunde handel oor die aard en funksie van kommunikasie en dikwels massakommunikasie in ons samelewing. Dit handel oor die aard van kontrole, die mate van uitspraak wat daar in die massamedia bestaan of behoort te bestaan. Dit is in die massamedia dat die proses van demokratisering sig manifesteer. Mag massamedia nog losstaan van die gemeenskap waarvan dit deel is? Is die $\mathrm{Ne}$ derlandse suile-stelsel waar elke groep met 'n gegewe getal lede 'n sekere tyd op die radio en TV toegeken word dalk die ideale sisteem? Of is dit die begin van die verval van die demokrasie ? Hierdie is vrae wat deur die teoretici gevra word en mense soos Raymond Williams, Marchal McLuhan, Collin Cherry, Guido Fauconnier, Kierkegaard en Ortega y Gasset se uitsprake word bestudeer.

Aan die praktiese of toegepaste kant kry ons byvoorbeeld effekstudies. Effekstudies is miskien van die bekendste en van die oudste studievelde in die kommunikasiekunde. Vrae wat gevra word is byvoorbeeld "Wat was die effek van hierdie of daardie propaganda-tegniek op 'n bepaalde groep ontvangers?" „Wat was die effek van hierdie of daardie struktuur van 'n mededeling?" „Wat was die effek van die of daardie kode op die ontvangers?', ens., ens. Die doel met effekstudies is nie bloot beskrywend nie maar die einddoel is om vas te stel watter kombinasie van die groot getal moontlikhede tot beskikking van die kommunikator sal die suksesvolste wees vir 'n bepaalde individu of vir 'n groep ontvangers in bepaalde omstandighede. Effekstudies is dus in wese nie verledegerigd nie maar wel toekomsgerigd in die sin dat daar gepoog word om riglyne op te stel vir meer doeltreffende kommunikasie. Effekstudies word op feitlik elke terrein van die lewe onderneem, byvoorbeeld in die politieke sfeer, in advertensies, in radio, rolprente, televisie, koerante, tydskrifte. Ander benaderings bestaan ook en dan ondersoek ons die effek van strukture, soos primêre en resente strukture of ons kyk na die effekte van kodebenuttings soos watter 
kleure was die doeltreffendste of ons kyk na aanbiedingsformate soos verhale versus gesprekke versus byvoorbeeld preke.

Uit al hierdie effekstudies sal 'n professionele kommunikator soos 'n skakelbeampte, reklame-agent, massamediadeskundiges en andere probeer om hulle eie skeppings te beoordeel en om elke keer beter en beter te vaar.

Ek wil u nou vra om saam met my 'n onmoontlike oefening uit te voer. Kom ons veronderstel dat die kerk 'n kommunikasiepraktisyn sou aanstel en opdrag gee om vas te stel wat die doeltreffendheid van die prediking in die kerk is en om aanbevelings ter verbetering voor te lê.

Daar is verskeie maniere waarop so 'n studie onderneem kan word maar ek wil u graag neem deur die stelsel van Doelgerigle Kommunikasie of D.G.K. 'n Stelsel vir die verhoging van doeltreffendheid wat ek 'n paar jaar gelede gepubliseer het en beter bekend is as C.B.O. (Communication by Objectives.)

Agtergrondstudie: Ons sal heel eerste probeer vasstel wat die posisie van die kerk in die samelewing is. Waar is die sterk punte, waar die swakkes. Word die kerk en sy boodskap aanvaar deur die samelewing? Hoe sien mense uit elke lewenssfeer die kerk ? Watter waarde het dit vir elke groep en sub-groep mense ? Daar is reeds sulke ondersoeke gedoen en deur die loop van die bespreking sal ek telkens verwys na twee studies van prof. C. Alant. Ek wil nie betrokke raak in ' $n$ bespreking van die meriete van die twee ondersoeke nie. Dit is nie my taak of my studieveld nie. Ek gebruik sekere statistieke uit die ondersoeke slegs as voorbeeld van moontlike bevindings wat 'n kommunikasiepraktisyn in so 'n hipotetiese ondersoek sou kon verkry en die invloed wat dit op die aanbevelings sal kan hê.

Alant het mense in drie klasse ingedeel sg: professioneles, Gegradueerders en Nie-akademies of in ekonomiese terme die hoër-, middel en laer ekonomiese klasse.

Sal ons kommunikasiekundige ook soos Alant vind dat slegs $60 \%$ van die laer ekonomiese klas, slegs $\pm 25 \%$ van die middelklas en slegs $\pm 40 \%$ van die hoër klas glo dat dit vir hulle geestelike welsyn noodsaaklik is om kerkdienste by te woon. Gemiddeld gee dit vir ons slegs $42 \%$ lidmate wat glo dat hulle eredienste moet bywoon. As die kerk en sy predikante glo dat lidmate dienste moet bywoon om na die boodskappe of preke te luister, dan het ons hier 'n geval van botsende oortuigings. Uit 'n bevinding soos hierdie sou ons kommunikasiepraktisyn reeds kan aflei dat die predikante nie slegs 'n voorligtingsfunksie het nie maar ook 'n oorredingsfunksie nl. om lidmate te oortuig dat dit vir hulle geestelike beswil nodig is om die kerk gereeld te besoek.

Behoeftes: Na so 'n algemene agtergrondstudie sal ons meer spesifiek na verskillende fasette van die prediking in die besonder begin kyk. Sal ons byvoorbeeld soos Alant vind dat gemiddeld slegs $\pm 30 \%$ van die lidmate erken dat hulle baie geestelike baat vind uit preke ?

Ek aanvaar dat alle kommunikasie uit behoeftes van die een of ander aard voortspruit. By die beplanning van die prediking sal dit volgens D G K nodig wees om ernstig te besin oor die behoeftes 
van die predikant én die behoeftes van die gemeente wat na die preek sal moet luister. Wat sou byvoorbeeld die godsdienstige behoeftes gewees het van 'n gemeente so 'n paar maande gelede toe Suid-Afrika se weermag Angola en Zambië binnegedring het? Hierdie vraag bring outomaties ander vrae na vore soos of die kerk en dus predikante, hoegenaamd preke moet voorberei wat 'n maatskaplike, sosiale of nasionale gebeurde as vertrekpunte het? Moet of mag predikante betrokke wees en „,betrokke-preke” opstel. Vanuit 'n kommunikasiekundige gesigspunt sal dit gesonde taktiek wees om die aktualiteit van die Christelike geloofslewe openlik of verskuild in feitlik elke preek in te werk. Dit is gegrond op die aanvaarding dat mense behoefte daaraan sal hê om die gebeurde van die dag, die lewenstendense van die tyd en die nasionale en internasionale ontwikkelinge volgens Christelike beginsels vertolk te kry. Ek moet dit duidelik maak dat ek nie 'n voorstander is van die sogenaamde ",sosiale prediking" wat byvoorbeeld in Nederland hoogty gevier het en waarvan $u$ en ek ondervinding het nie. Daar is vir my 'n duidelike onderskeid tussen sosiale prediking (wat dikwels niks meer is as politieke preke) en Christelike vertolking van gebeurde.

Boodskap: As een van die eerste drie stappe in DG $\mathrm{K}$ sal 'n duidelike boodskap of boodskappe geformuleer word. 'n Boodskap is die kernbetekenis van 'n mededeling. Ons kan meer as een boodskap met dieselfde mededeling kommunikeer. Boodskappe kan openlik of verskuild gekommunikeer word en die predikant moet van dié onderskeid bewus wees want 'n verkeerde besluit in hierdie vroeë stadium sal die preek laat misluk. Wat moet openlik en wat moet verskuild gekommunikeer word? Mens hoor soms die opmerking dat daar niks in die Christelike leer is wat weggesteek moet word nie en daarom moet alles in verband met die Christelike geloof openlik meegedeel word. Die standpunt is kommunikasiekundig nie aanvaarbaar nie want dit is meer as dikwels vir 'n kommunikator noodsaaklik om sy toehoorders of bestemming toe te laat om die ware boodskap sélf te ontdek. In so 'n geval sal dit vir 'n predikant nodig wees om slegs genoeg kommunikasie-elemente in die regte volgorde te verskaf sodat die gemeentelede sélf die boodskappe kan ontdek. Iets wat mens self ontdek is dikwels van blywender aard as dit wat openlik gegee word.

Die kodering van verskuilde boodskappe is egter iets wat noukeurig en met sorg beplan moet word.

In ons aanbevelings sal ons moet vra dat die kerk ernstig moet besin oor wat sy boodskap of boodskappe is. Hierin lê 'n probleem opgesluit want as die kerk gekoördineerd in sy boodskappe moet wees, sal ons die spontaniteit en individualiteit van die predikante verloor. Die vraag wat onmiddellik na vore kom is of ' $n$ swakheid van die kerk nie juis geleë is in die gediversifiseerdheid en die individuele standpunte van sy ampsdraers nie? Kan die vorige gedagte ten opsigte van aktualiteitsprediking ooit werklikheid word? Gaan die lidmate almal dieselfde leiding van hulle onderskeie predikante ontvang? Is dit veiliger om liewers te bly in die algemene, die oorkoepelende en nooit betrokke te raak in die aktualiteit van 
die daaglikse bestaan van die individuele lidmaat nie? In die algemene boodskap is daar ' $n$ implisiete veiligheid en eenvormigheid. In die spesifieke is daar die gevaar van diversiteit, meningsverskille en op sy uiterste verbrokkeling.

Doelwitte: Die laaste van die inleidende drie stappe in enige kommunikasie is die formulering van doelwitte. Net soos met boodskappe kan ons meer as een doelwit met 'n mededeling hê. Daar kan ook openlik en verskuilde doelstellings wees. Mens kan langtermyn, medium-termyn of kort-termyn doelwitte hê. Die werkwoorde in die geformuleerde doelwit bepaal tot 'n hoë mate die strategie wat gevolg moet word. As die doel is om in te lig tree mens anders op as wanneer jy idees wil verander. As jy wil oorreed, tree jy anders op as wanneer jy standpunte wil verstrek - om maar enkeles te noem.

Mens kan die vraag vra hoeveel predikante besin nog na 'n paar jaar in die bediening gereeld in diepte oor sy doelwitte met elke preek wat hy voorberei of is die algemene, oorkoepelende doelwit van die verspreiding van die Evangelie àl wat in gedagte gehou word? Word daar oit besin oor wat die gemeente moet doen of glo of weet nadat hulle na 'n preek geluister het? Of is die predikant tevrede dat hy ,die skrifte uitgelê het?"

Wins: Iets waaraan elke kommunikator en dus ook predikante aandag moet gee is die winsgewendheid van sy kommunikasie. Wins word nie noodwendig in terme van geld uitgedruk nie - wie kan in elk geval 'n geldelike prys stel op bekering van een enkele persoon? Die insette in kommunikasie kan gewoonlik teruggevoer word na geld, mannekrag, masjiene, materiaal, tyd en moeite. As enige van die komponente of as die gesamentlike inset uit die bronne te hoog raak is 'n kommunikasie onlonend. As 'n predikant byvoorbeeld tagtig tot negentig uur sou spandeer aan die voorbedeiding van ' $n$ preek wat 'n halfuur duur, dan moet mens begin wonder of dit lonend is. As hy egter tagtig tot negentig uur spandeer aan die onderrig van tien katkisante oor 'n tydperk van weke dan maak die inset $\sin$.

Die punt van dalende-meeropbrengs is ook vir predikante van belang. Dit is daardie punt waar 'n persoon sy inset aansienlik moet vergroot om 'n kleinerige verhoging in winste te verkry. Dit maak nie saak hoe of in watter terme die winste bereken word nie.

Kommunikasie-elemente: Kommunikasie-elemente is enigiets wat in die kommunikasie gebruik kan word. Woorde, gedagtes, statistiek, grappe, inligting, gelykenisse, stories, gedigte - enigiets wat gebruik kan word. Aanvanklik word te veel kommunikasie-elemente versamel sodat mens seker is dat die volle spektrum gedek word. Later word die doeltreffendstes geselekteer. Seleksie word teen doelwitte getoets. Alles wat inpas by die doelwitte word behou. Alles wat nie daarby pas nie, word verwerp. Selfs op hierdie stadium word daar meestal meer as een element wat dieselfde betekenis het, versamel sodat daar later aan herhaling aandag gegee kan word.

Bestemming: Slegs daardie ontvangers wat 'n behoefte aan die boodskap het en wat die bevattingsvermoë daarvoor het, is die be- 
stemming van 'n boodskap. In elke kerk met elke preek is daar mense wat nie die vaagste benul het van die boodskap wat aan hulle oorgedra word nie. Hulle ontvang dit wel, hulle hoor dit maar hulle is nie die bestemming daarvan nie.

Een van die belangrikste stappe in enige kommunikasieprogram is die ontleding van die bestemming. Voordat 'n program van stapel laat loop word, sal ons weet wat die demografiese eienskappe van die bestemming is. Hoeveel mans, hoeveel vrouens, hoeveel tieners, hoeveel kinders, ouderdomme, beroepe, opvoedingspeil, sosiale, politieke en religieuse affiliasies. Ons sal weet wat die hoogste, laagste en gemiddelde bevattingsvermoë van die bestemming is. Hoeveel en wat hulle reeds van die onderwerp weet. Ons sal weet wat hulle media- en kodevoorkeure is en nog talle ander kenmerke sal noukeurig bestudeer word.

In terme van die boodskap en die doelwitte sal ons dan begin sif aan die kommunikasie-elemente en slegs dié behou wat binne die vermoëns van die bestemming val.

Hoeveel predikante kan sê dat hulle met elke preek so 'n ontleding doen? Nou is dit so dat predikante veronderstel is om te weet wie hulle bestemming is. Hulle ken immers hulle gemeentelede - dikwels by naam. Hoekom is dit dan dat soveel van die preke nie inslag vind nie? Is dit slegs toe te skryf aan die ,swak ontvangs" daarvan? Lê die skuld by die gemeente of by die predikant? Ons kom later weer hierop terug wanneer ons oor die vlak van kodering praat.

Kommunikator: In enige kommersiële kommunikasie sal ons baie noukeurig kyk na die persoon wat as kommunikator moet optree. Dit is nie altyd so dat iemand wat ' $n$ idee kry juis die beste persoon is om daardie idee aan ander mense te kommunikeer nie. Laat ons egter vir die doel van hierdie artikel aanvaar dat alle predikante in alle omstandighede die geskikste persoon is om die preek te lewer.

Wat vir ons "ondersoek" egter van belang is, is dat daar meningsverskil bestaan oor wie die werklike mededeler in die kommunikasieproses is. Is dit God of is dit predikant. As dit God is dan is die predikant slegs 'n medium wat gebruik word. As dit so is dan sal ons in ons ondersoek verwag dat alle predikante ten opsigte van 'n bepaalde saak dieselfde boodskap sal oorbring. As dit nie so is nie dan moet ons aanvaar dat 'n predikant nie slegs medium is nie maar ook mededeler in sy eie reg.

Nietemin, laat ons bly by ons aanvaarding hierbo, nl. dat die predikant die geskikte kommunikator is.

Omstandighede: Ons sal noukeurig oplet na die mikro- én makroomstandighede waarin die kommunikasie gelewer gaan word. Alles wat moontlik die sukses van die kommunikasie kan benadeel sal 'n plan mee gemaak word. Laat ons aanvaar dat die omstandighede vir predikante deur die eeue geyk is: Daar is 'n kerkgebou, slegs die predikant word toegelaat om te praat, toehoorders moet stilsit, gerase word tot die minimum beperk of deur argitektoniese beplanning of deur die tradisie van die eeue. 
Tydsberekining: Wat tydsberekening betref, is daar in die private sektor altyd bekommernis want daar is 'n regte en 'n verkeerde tyd om 'n mededeling te maak. Weer eens het ons met sogenaamde algemene en spesifieke tye te doen. Die ekonomiese klimaat van die wêreld vereis byvoorbeeld van 'n minister om iets daaroor te sê. Dit is algemene of oorkoepelende tydsaspekte. Maar gaan hy dit op die $9 \mathrm{e}$ of $10 \mathrm{e}$ van die derde of vierde maand sê. Gaan hy dit in die oggend of in die aand sê ? Dit is sogenaamde spesifieke tydsaspekte.

Vir predikante in hul prediking geld slegs die algemene want die spesifieke tyd vir die lewering van sy preek is vooraf bepaal. 10 uur elke Sondagoggend en 7 uur elke Sondagaand. Of dit die mense pas of nie word selde of ooit gevra.

So: die tydstip van lewering is vas.

\section{Benaderingswyse:}

Ons kan mededelings op vier skale beoordeel.

Ernstig, Humoristies, Rasioneel en Emosioneel. Daar is navorsing gedoen wat aantoon dat elk van die benaderingswyses vir besondere omstandighede die geskikte is. 'n Goeie kommunikator sal sy benaderingswyse beplan sodat dit inpas en aanpas by sy boodskap en die doel wat hy wil bereik.

In ons kerk is preke sonder uitsondering ernstig en byna sonder uitsondering rasioneel. Emosionaliteit in preke word nie geduld nie en humor mag nooit gebruik word nie. Die indruk wat 'n oningewyde analis sou vorm is dat die boodskap van die Evangelie naamlik dat daar vergifnis van sonde is, dat daar 'n Middelaar vir ons is en dat daar 'n ewige lewe op die gelowiges wag, dat dié boodskap 'n ernstige saak is, dat dit 'n saak suiwer vir die verstand is, dat mense nie emosies daaroor mag vertoon nie en dat daaroor geen grap te maak is nie.

\section{Formate:}

Die term „formaat" is oorspronklik gebruik en word vandag nog grootliks gebruik om die grootte van 'n boek of ander publikasie an te dui: Dus die eksterne waarneembare afmetings of vorm. Die kommunikasiekunde het die term oorgeneem en verwys daarmee ook na die vorm van 'n mededeling. Verskeie formate word onderskei soos artikels, stories, prente, driedimensioneel, musiek en vokale formate. Laasgenoemde is die enigste formatgroep wat in prediking gebruik word. Daar kan wel binne 'n preek van ander formate gebruik gemaak word soos wanneer 'n storie of 'n gelykenis in die preek ingeweef word.

\section{Tempo:}

Die tempo van lewering van 'n mededeling is besonder belangrik en dit word bepaal deur die vermoëns van die ontvanger of meer bepaald die van die bestemming. Tempo kan omskryf word as die snelheid waarmee nuwe kommunikasie-elemente mekaar opvolg. Tempo kan op twee maniere gemanipuleer word: Eerstens 
tempo van lewering. Dit is 'n meganiese wyse van manipulasie soos wanneer mens vinniger of stadiger praat.

Tweedens, is daar strukturele manipulasie waar die kommunikasieelemente binne die mededeling só gerangskik word dat hulle vinniger of stadiger op mekaar volg. As ' $n$ tempo hoog is, sal $u$ die aandag van die minder begaafde persoon verloor. As die tempo te laag is, sal u die aandag van die meer begaafde persoon verloor. Die predikant wat nie aandag gee aan die tempo van sy preek nie, sal verseker dikwels 'n gedeelte van sy gemeente nie bereik nie.

\section{Struktuur:}

Daar is minstens nege strukture wat 'n kommunikator kan gebruik en gewoonlik vind mens in 'n mededeling nie 'n enkele suiwer struktuur nie want vermengings van die nege is die normale stand van sake. Strukture word gewoonlik geĩdentifiseer op grond van die verbande wat daar tussen die onderskeie kommunikasie-elemente bestaan. Met induktiewe strukture word van die besondere of spesifieke na die algemene gevorder, met deduktief van die algemene na die spesifieke. Met 'n klimakstruktuur kom die belangrike element laaste. Met 'n anti-klimakstruktuur is die belangrikste element eerste, ens.

Preke het normaalweg 'n induktiewe-klimaatstruktuur en baie selde word daarvan afgewyk. Daar kan hiermee nie veel fout gevind word nie, want dit is volgens navorsing een van die doeltreffendste struktuurvorme veral met bo-gemiddelde intelligente mense.

Kodes: 'n Kode kan omskryf word as 'n groepering van tekens en/ of simbole op grond van een of meer gemeenskaplike eienskappe tesame met die reëls vir die gebruik van die tekens of simbole in kommunikasie. So is 'n taal 'n kode, skriftekens vorm 'n kode, kleur is 'n kode. Ons onderskei verder ook nog kinetiese kodes of die nieverbale kodes; proksemiese kodes of die ruimtelike verhoudings tussen persone, grafiese kodes, drie-demensionele kodes en talle klankgeboude kodes soos intonasie, beklemtoning, pouses, embolafriasa, aksente, musiek en talle ander.

In prediking word hoofsaaklik vokale kodes gebruik. Taal, intonasies, beklemtonings en pouses. Daarmee saam beperkte handgebare en beperkte wisseling in gesigsuitdrukkings. Nou is dit interessant om te let op die woordeboek-omskrywing van "preek". Op Engels lees ons: „preach: Deliver sermon or religious address".

Gaan ons nou die woord ,sermon" na, kry ons "Discourse delivered from pulpit and usually based on text of Scripture, by way of religiuos exhortation or instruction, similar discourse on religious or moral subject delivered elsewhere or published". ce".

Die woord "address" gee vir ons: „Discourse delivered to audien.

En laastens gee „discourse": „Talk, conversation, dissertation, treatise, sermon, ... converse, hold forth in speech or writting on a subject".

Hieruit blyk dit dan duidelik dat preke verbale mededelings is en dat dit soms ook gepubliseer word. As ons hierdie opvattings on- 
dersteun moet ons aanvaar dat die prediker slegs die bestaande. gewone kodes kan gebruik want 'n preek is mos 'n verbale mededeling aan 'n groep mense. Of die kerk kan bekostig om by hierdie standpunt te bly is ' $n$ vraag wat ons sal moet beantwoord.

Media: Die volgende stap in 'n kommunikasieproses is die seleksie van 'n medium of van media om die boodskap mee oor te dra. Daar is tientalle media tot beskikking van die kommunikator maar die prediker in sy prediking gebruik normaalweg slegs een naamlik die van spraak. Selfs wanneer radio en televisie of drukwerk gebruik word, word daar geen of weinig aanpassings gemaak vir die eise van die medium. Feitlik elke uitgesaaide preek (Radio of TV) en elke gepubliseerde preek kon net sowel vanaf ' $n$ preekstoel in 'n kerk gelewer gewees het.

Ons sal in ons ondersoek aandag moet gee aan alternatiewe media en alternatiewe koderingsmoontlikhede. Die moderne mens bevind homself in 'n mediaryke samelewing. Media wat voortdurend benut word en wat boodskappe dra wat kompeteer vir die aandag van die lidmate. Kan die Boodskap nie ook op ander maniere oorgedra word nie? Moet ons blind wees vir die feit dat mense van mekaar verskil en dat elke mens ander voorkeure het? Sommige hou daarvan om te luister, ander wil lees, ander wil kyk, nog ander verkies verhale en party verkies feite en 'n logiese betoog.

Die media-rykdom van ons beskawing het daartoe gelei dat antropoloë primitiewe beskawings dikwels as verbale kulture beskryf. Met ander woorde mense wie kultuurgoedere verbaal gehandhaaf word. Kan die kerk met prediking alleen volstaan?

Kodering: Die prediker kies sy woorde, skryf sy sinne neer, besluit watter elemente herhaal moet word, op watter plek 'n gelykenis of wat ookal moet inkom. In kommunikasie-sin is dit op hierdie punt dat kommunikatore dikwels fouteer.

Ek het drie preke ontleed. Een van elk van die drie susterskerke. Die preke was almal uitgesaai oor die radio, twee was oggend preke en die ander ' $n$ aandpreek. Twee indekse is toegepas - die Flesch Leesbaarheidsindeks en die Flesch Interessantheidsindeks.

Die Leesbaarheidsindeks word verkry deur die gemiddelde lengte van sinne en die aantal lettergrepe per 100 woorde deur middel van 'n formule met mekaar in verband te bring en is gebaseer op die feit dat dit moeiliker is om lang sinne, veral as hulle, soos hierdie een, deur verskeie bysinne, wat almal ook nog taamlik lank kan wees, onderbreek en/of aangevul word, met die eerste deurlees of aanhoor te verstaan en korrek te vertolk.

Die tweede komponent van die leesbaarheidformule neem in ag dat lang woorde met verskeie lettergrepe moeiliker is as kortes met slegs een lettergreep.

Die twee komponente word deur middel van 'n formule geïntegreer en lewer dan 'n syfer tussen nul en 100. Nul is baie moeilik, feitlik onleesbaar en 100 is baie maklik vir enige persoon wat maar kan lees.

Die drie preke se indeks is soos volg:

$N G=60$ Op Flesch se indeks is 60 die snypunt tussen "standaard" 
en ,redelik moeilik”. Ten einde „standaard” of „redelik moeilik” reg te kan vertolk het dr. C. L. Koekemoer van RAU dit in verband geplaas met terme wat binne ons verwysingsraamwerk is. Volgens Koekemoer sal iemand die standaardgraad kan begryp as hy standerd vier of vyf geslaag het. Vir die ,redelik moeilike" graad moet 'n persoon tussen standerd ses en nege geslaag het.

Hervormde preek: $65 \mathrm{Op}$ die indeks is dit 'n ,redelik moeilike" klas. Gereformeerd $=60$ Dit wil sê, dieselfde as die van die NG-predikant.

Voordat ons tot gevolgtrekkings kom oor hierdie syfers moet ek net op twee punte wys. In die eerste plek is die indekssyfers verkry met 'n steekproef uit elke preek. Die steekproewe is verteenwoordigend maar dit kan natuurlik gebeur dat mens ander syfers kan kry met ander steekproewe. So weet ek byvoorbeeld dat daar sinne met 52 en 55 woorde in een van die preke voorkom maar dit val nie in een van die steekproewe nie. Tweedens moet ek u daaraan her. inner dat die indeks 'n leesbaarheids-indeks is en nie 'n hoorbaarheidsindeks nie. Daar is nog nie 'n leesbaarheidsindeks ontwikkel nie en my vermoede is dat dit 'n totaal ander indeling sal verskaf. Die leeshandeling is iets anders as die luisterhandeling. Met leeswerk bepaal mens jou eie tempo en jy kan oor en oor lees totdat jy begryp. Spraak word liniêr ontvang, die luisteraar bepaal nie die tempo nie hy kan nie teruggaan nie. Laat ons dit daar laat en aanvaar dat die drie preke wat ontleed is, nie buitengewoon moeilik was nie.

Flesch het nog 'n indeks ontwerp wat hy die ,human interest score" noem. Ek verkies om dit in Afrikaans die ,betrokkenheidsindeks" te noem. Die indeks word verkry deur die persentasie sogenaamde ,persoonlike" woorde om die persentasie sogenaamde ,persoonlike" sinne met mekaar in verband te bring deur middel van 'n formule.

Persoonlike woorde is alle voornaamwoorde, alle woorde wat na een van die geslagte verwys en alle woorde wat na 'n mens of mense verwys.. Persoonlike sinne is sinne wat op skrif in aanhalingstekens aangedui word soos wanneer ons aandui dat iemand praat, verder ook nog alle onvoltooide sinne wat die leser of luisteraar self moet voltooi, ook vrae, opdragte en versoeke wat direk aan die luisteraar gerig word en dit sluit verder alle uitroepe in. Dit is dus tegnieke wat die ontvangers betrokke kry by die boodskap.

Hierdie indeks vir die drie preke is soos volg:

N.G. $49=$ Baie Interessant

Hervormd: $48=$ Baie Interessant

Gereform.: $45=$ Baie Interessant

Dit kom op die oog af voor asof die indeks meer betroubaar is as die ander een maar van die sogenaamde persoonlike woorde wat bygetel moes word is God, Jesus, Christus, Heilige Gees, en die name van Bybelboeke wat almal dié sake is waaróor die prediking handel en is nie betrokkenheidswoorde in die eng sin van die woord nie. Indien dié woorde uitgelaat word maar woorde soos sy of hy wat verwys na God of Christus of die Heilige Gees beskou word, verlaag die indeks reeds na syfers tussen $20 \%$ en $40 \%$ wat bloot as interessant aangedui word, d.w.s. laer betrokkenheid. 
Die toepassing van die indekse is een manier om na die inhoud van preke en ander kommunikasies te kyk. Daar is nog ander metodes maar dit is nie moontlik om dit hier te bespreek nie.

Toetsing In die kommersiële wêreld soos by advertensies word 'n gekodeerde mededeling altyd eers getoets voordat die versprei word. In die geval van preke is dit nie altyd moontlik nie en ervaring behoort die predikant te lei.

Lewering Dit is die werklike oordrag van die boodskap. Die werklike preek self. In hierdie opsig is predikante gewoonlik goed voorberei vir hulle taak as verbale kommunikatore.

Terugvoering Enige professionele kommunikator sal sorg dat hy terugvoering van sy gehoor kry. Op watter wyse terugvoering verkry word is nie so belangrik as die feit dat dit verkry moet word en dat dit betroubaar moet wees. $\mathrm{Na}$ die beste van my wete beplan predikante selde of ooit 'n besliste prosedure vir terugvoering. Ek gee toe dat daar wel terugvoering is maar kom dit nie dikwels van

geesdriftige gelowiges wat graag met die predikant of met enigiemand oor geloofsake of oor kersake praat nie? Wat van die stilswyende tagtig of negentig persent?

Beoordeling Terugvoering word nie net eenvoudig vir algemene kennis verkry nie, dit vorm ' $n$ integrale deel van die professionele kommunikator se bestaan en voortbestaan want hy gebruik sy terugvoering om sy eie doeltreffendheid mee te beoordeel. Hoe suksesvol was hy? Watter mense het hom verstaan? Maar belangriker nog, watter mense het hom nie verstaan nie? Daar is dus 'n voortdurende proses van selfondersoek, self-evaluering en selfverbetering aan die gang. Is dit die geval met ons predikante?

„Verslag" Nadat ons deur die stappe gegaan het, en ek moet u daaraan herinner dat ek dit slegs oorsigtelik gedoen het, sal ons analis met aanbevelings moet kom. Hoe sal so 'n verslag daaruitsien?

Ons sal begin met ' $n$ beskrywing van die huidige toestand. Die stand van sake. Wat is die dominante boodskappe, doelwitte en behoeftes van die Kerk soos gemanifesteer in en deur sy predikante. Dit sou ons vergelyk met die behoeftes van die bestemmingsgroepe. Ons sou byvoorbeeld noem dat $80 \%$ van die lidmate nie onvoorwaardelik glo in die uitverkiesingsleer nie of dat $38 \%$ van die jongemense tussen $16-20$ jaar glo dat kerklidmaatskap nie noodsaaklik is vir hulle redding en saligheid nie.

Ons sou kennis geneem het van 'n bevinding dat die kerk en kerklidmaatskap nou geassosieer word met die bestaande orde (tradisionele politieke bedeling) afgesien van die prediking want die ten dens kom by alle kerkgroepe voor, Afrikaans, Engels en denominasies.

Ons sou ernstig kennis geneem het van die feit dat die huidige geslag tieners en vroegvolwassenes 'n betrokke geslag is, dat hulle nie daarvan hou om pasief te wees nie. Hierdie feit manifesteer sig ook in die media wat gerig is op dié groep mense.

Hieruit sou mens reeds kon aflei dat daar behoefte is vir drie soorte preke nl. bevestiging of versterking van die opvattings aan die groep wat as meelewende gelowiges geklassifiseer kan word; oorredingspreke vir die groep wat nie juis omgee nie of wat twyfel 
of bevraagteken, en laastens aktiverende preke vir die jonger mense wat graag betrokke wil raak in die een of ander aktiwiteit.

Indien ons die voorafgaande as doelwitte aanvaar sal daar ernstig gekyk word na die kommunikasie-elemente wat vir elk van die drie groepe nodig is. Ons sal ook noukeurig aandag gee aan die media en formate wat gebruik moet word. Waarom kan daar nie soms besprekingsdienste wees nie. Waarom kan oudiovisuele hulpmiddels nie gebruik word nie of is kerkgeboue gereserveer vir spraak deur slegs een persoon - die predikant? Is die vorm van die erediens so vas, so onveranderbaar dat die vorm reeds ' $n$ mate van heilige onaantasbaarheid verwerf het?

Oorweging sal geskenk word aan meer aktualiteitsprediking die vertolking van belangrike gebeurde in terme van Christelike waardes.

Hierdie paar opmerkings kan maklik tot gevolgtrekking lei dat kommunikasiekundiges in die algemeen of dan ek in die besonder graag sal wil meedoen aan die verwêrelding van die evangelieverkondiging, aan die vervlakking van godsdiensbeoefening en om toestande te skep wat steurend gaan wees as gevolg van die sirkusagtige vertonings wat met sommige multimedia programme geassosieer word.

Dit sal jammer wees as dit u gevolgtrekking is, want dit is nie my bedoeling nie.

Maar miskien sou u 'n ander verslag geskryf het?

Gelewer voor die GTV Pretoria 22 Mei 1978. 